\title{
10 Rehabilitating a Textile Plant for Barcelona's Les Corts Neighbourhood Library
}

\begin{abstract}
The Montserrat Abello library is the most recent public library to be opened in the city of Barcelona. The library occupies a former textile plant built in 1924. The project gives new life to a symbolic building in the Les Corts neighbourhood and evokes its history. An industrial building is designed to be a self-contained complex operating independently within its environment. Its operation is the opposite of what is required of a public library, which should relate closely to its surroundings and its neighbourhood. The assignment of a new use to an industrial building in the city enables the structure to continue, despite its location. Rehabilitation and reuse should respect the building's values and key features and ideally correct any shortcomings, without changing its essential character. Establishing a clear connection between the interior and the exterior was one of the major challenges of the project. The project was carried out with a sustainability and energy efficiency agenda including gaining BREEAM Certification.
\end{abstract}

Keywords: Public libraries - Spain; Library buildings - Design and construction; Textile factories - Remodelling for other use

\section{Introduction}

The Barcelona Libraries Plan 1998-2010 (https://ajuntament.barcelona.cat/ biblioteques/en/canal/pla-de-biblioteques; https://ajuntament.barcelona.cat/ biblioteques/sites/default/files/pla_0.pdf) and its 2010 update, the Barcelona Libraries 10 Years+ Plan (http://www.bcn.cat/biblioteques/docs/bib10anys_eng. pdf; https://ajuntament.barcelona.cat/biblioteques/en/canal/pla-de-biblio teques), were the strategic documents that guided the deployment and location of the city's network of library facilities. Twenty years after its initial approval, the plan has been implemented as follows: 23 new libraries have been opened; 15 more have been refurbished; and some adaptations have been carried out in another 40 facilities, with a total of $65,767 \mathrm{~m}^{2}$ devoted to library services. The Biblioteca Montserrat Abelló/Montserrat Abelló Library, which opened on 28 January 2018 (Figures 1, 13), was the last major rehabilitation project although some work

Ә Open Access. (2021 Ricard Mercadé Rogel, Aurora Fernández Grané and Jordi Gual Nevado, published by De Gruyter. (cc) BY-NC-ND This work is licensed under the Creative Commons Attribution-NonCommercialNoDerivatives 4.0 International License. 


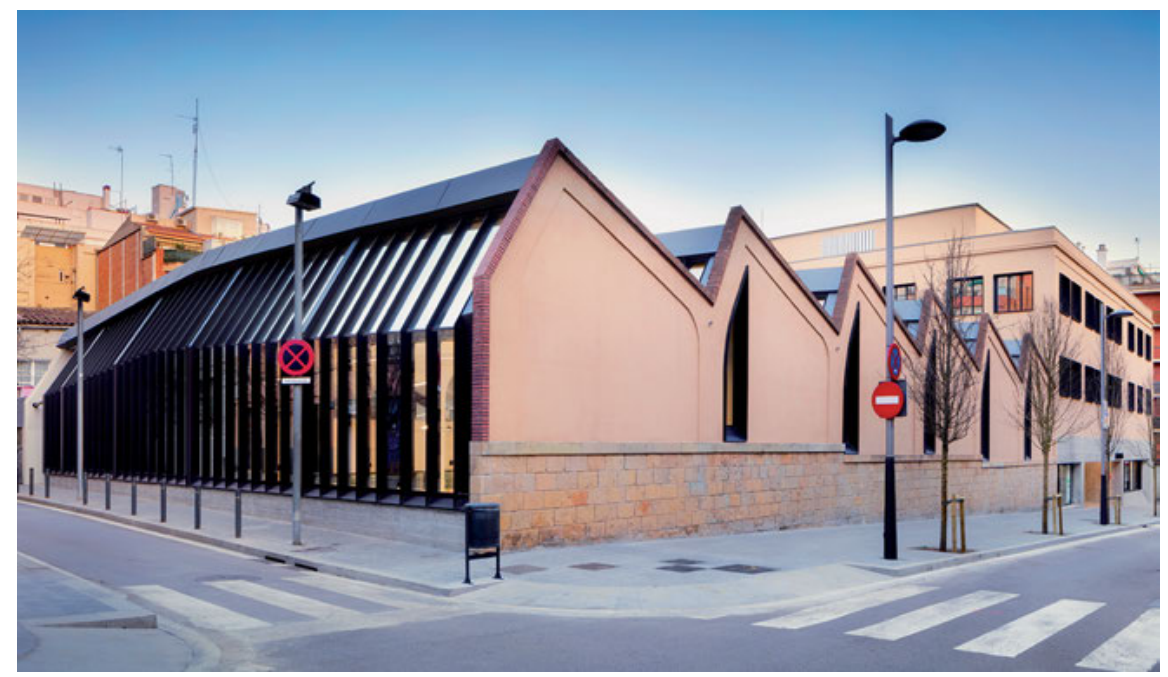

Fig. 1: Les Corts Neighbourhood Library. @ David Cardelús.

\section{Facts and Figures}

Name: Biblioteca Montserrat Abelló

Address: Carrer Comtes de Bell-Lloc, 192-200, 08014 Barcelona, Spain

Website: http://www.barcelona.cat/bibmontserratabello

Opening: January 2018

Builder: UTE Ferrovial-Deco

Architect: Ricard Mercadé Aurora Fernández arcquitectes SLP http://mercadefernandez.com/ Gross floor area: 3,760 $\mathrm{m}^{2}$

Main floor space: $1,687 \mathrm{~m}^{2}$

Collection size: 42,000

Staff: 14

Workstations: 40

Building costs: $€ 10,013,000$

remains to be done and work is underway on new facilities still to be opened in some of the city's neighbourhoods.

The Montserrat Abelló Library located at Carrer Comtes de Bell-lloc is the central library of Barcelona's Les Corts neighbourhood, serving a potential population of 82,182 residents. The investment to carry out the work totalled 10.013 million euros, including equipment and furnishing. The library's name is a tribute to the poet and translator Montserrat Abellói Soler (https://en.wikipedia.org/wiki/ Montserrat_Abell\%C3\%B3_i_Soler) who was born in Tarragona in 1918 and died 
in Barcelona in 2014. She was awarded literary prizes over the course of her long career and active in feminist movements from the 1970s. Her name was chosen for the library by Les Corts Women's Panel to commemorate the centenary of her birth.

The library occupies a former textile plant Gabriel Benet Campabadal built in 1924 (Figure 2). It was subsequently used by the Glass Centre Foundation. The design work on the site's reuse was carried out by the architects Ricard Mercadé and Aurora Fernàndez.

The library and Les Corts L’Ateneu de Fabricació digital/Digital Manufacturing Athenaeum or Fab Lab, a creativity and training space linked to new technologies and especially to 3D digital modelling and software, are both located within an area of a little over 4,000 $\mathrm{m}^{2}$. The floor space is considered appropriate since it complies with the plans agreed on during the project phase and meets all functional requirements. The purpose of the space is to encourage residents to develop ideas into products useful to society. The library and the Athenaeum provide access to information and knowledge; they share premises, resources and equipment and cooperate and conduct joint projects, thereby increasing the potential of each.

The Montserrat Abelló Library has holdings of 42,000 items: 34,700 books, 7,300 audiovisual items and 150 periodical subscriptions. The library specialises in maker culture, has a specialist collection of material focused on social inclusion and recently opened the Asimov Collection specifically devoted to science fiction.

\section{Towards a New Library Model}

The programming and planning phase prior to the start of the new project involved a process of reflection on the library model with the participation of professionals from different libraries. Various sessions were held to discuss, based on accumulated experience, what some of the spaces should be like and what uses were envisaged for the years to come. As a result, some changes were made to what had been foreseen in the initial functional brief. Changes could be implemented because the furniture plans had not been drafted and the final layout could still be modified. The aim was to focus on uses and users, seeking to ensure that everyone found his/her own space in the library.

Perhaps the most significant change was the reduction of shelving and the size of the collection with the initial holdings decreasing from 60,000 to 40,000. The reduction enabled space to be freed-up for use by people, and for events and group activities. It also made it possible to provide many more spaces where the collections could be better displayed. Another notable outcome was that the 
new furniture layout provided greater flexibility. Although a conference room, two support spaces and a classroom with computers for delivering digital literacy courses were already envisaged, it was considered desirable to hold some activities in open areas. To enable this, flexible furniture was sourced that would permit the spaces to be configured easily in different ways.

The introduction of the modifications did not entail radical change to the earlier plans but marked a move towards a new library model in which social exchange and the active participation of users would acquire greater prominence. Uses are changing their habits gradually but the demand for books and for places to study, read newspapers or connect to the Internet continues to exist and more traditional uses should still be kept in mind when designing new libraries or remodelling existing ones.

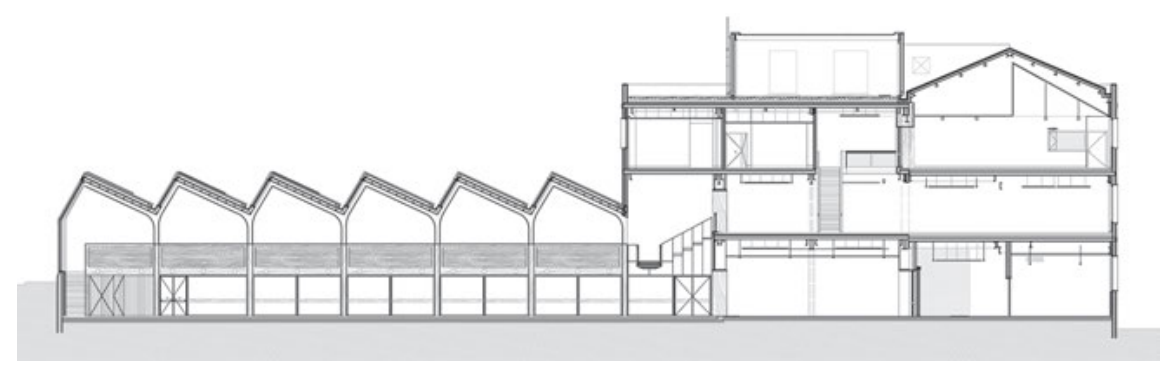

Fig. 2: Longitudinal section plan. @ Ricard Mercadé Aurora Fernández arcquitectes.

New libraries should continue to be what they have always been: spaces of discovery and learning with reading and access to knowledge as the fundamental pillars. In the modern world, however, they also need to be places for community participation where people can create, share and disseminate knowledge. These ideas formed part of the planning phase of the project and the architectural result successfully embraces the approach, fulfilling all requirements and allowing for the diversity of needs and uses of which libraries must be cognisant in the $21^{\text {st }}$ century.

\section{Layout of Spaces}

The rehabilitation project provided the library with a net area of 3,368 $\mathrm{m}^{2}$ distributed between an entrance hall, a mezzanine and two upper floors, with special spaces for children and for young people. On the ground floor there is a welcom- 
ing entrance and reception area, shared with the Digital Manufacturing Athenaeum, where users can borrow or return material using the self-service facilities. The reception area leads to a large open adult area displaying fiction, music and film collections and providing areas for group activities. The children's area, with access to an outdoor terrace, is also on the ground floor (Figure 3).

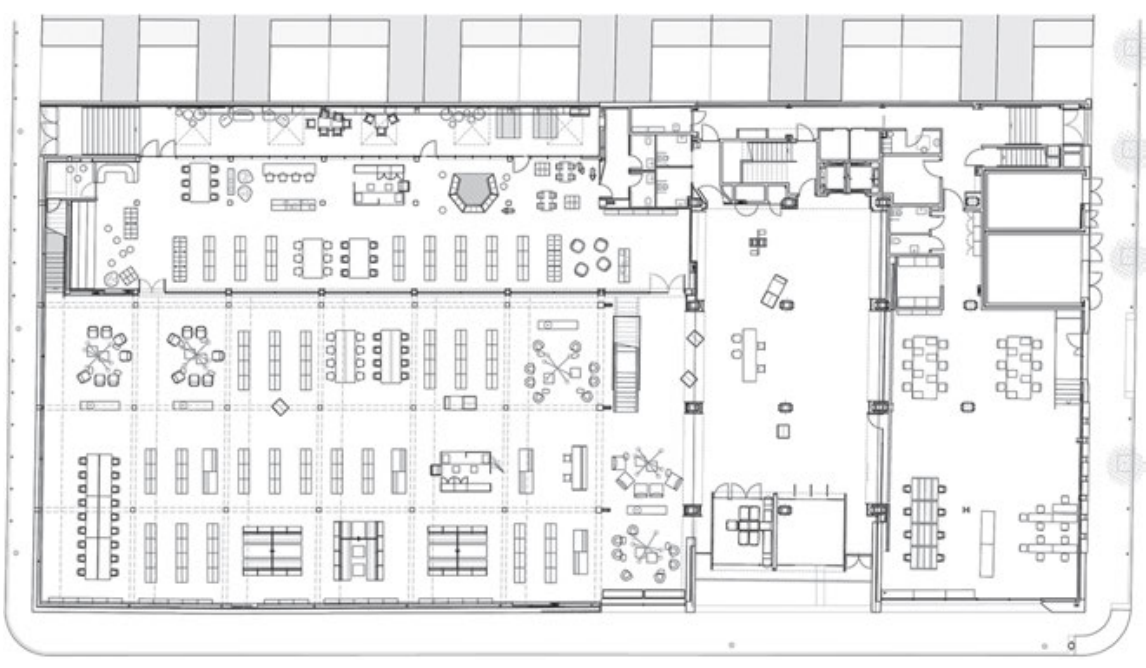

Fig. 3: Ground floor plan. (c) Ricard Mercadé Aurora Fernández arcquitectes.

The building programme considered the need to provide a special transition space for young people, with an offering distinct from that of other areas. The $200 \mathrm{~m}^{2}$ of the mezzanine were used to provide a specific fit-out for young people, combining an area with collections attractive to young people including comics, manga, teenage fiction and fantasy and anime cinema, with spaces for studying and working in groups. The first floor of the library, which is the site of the non-fiction holdings, is perhaps the quietest place in the whole building for silent study and peaceful reading (Figure 4).

On the second floor is the conference room with a capacity for 100 people and two support spaces for activities and workshops with a smaller capacity accommodating 20-30 people. Also located on this floor are the administration and staff work areas, and a CD storeroom with a capacity for 17,000 items. One of the project requirements was that the conference room should remain open when the rest of the library is closed. Movable partitions in the entrance hall allow direct access from outside the building to the second floor. 


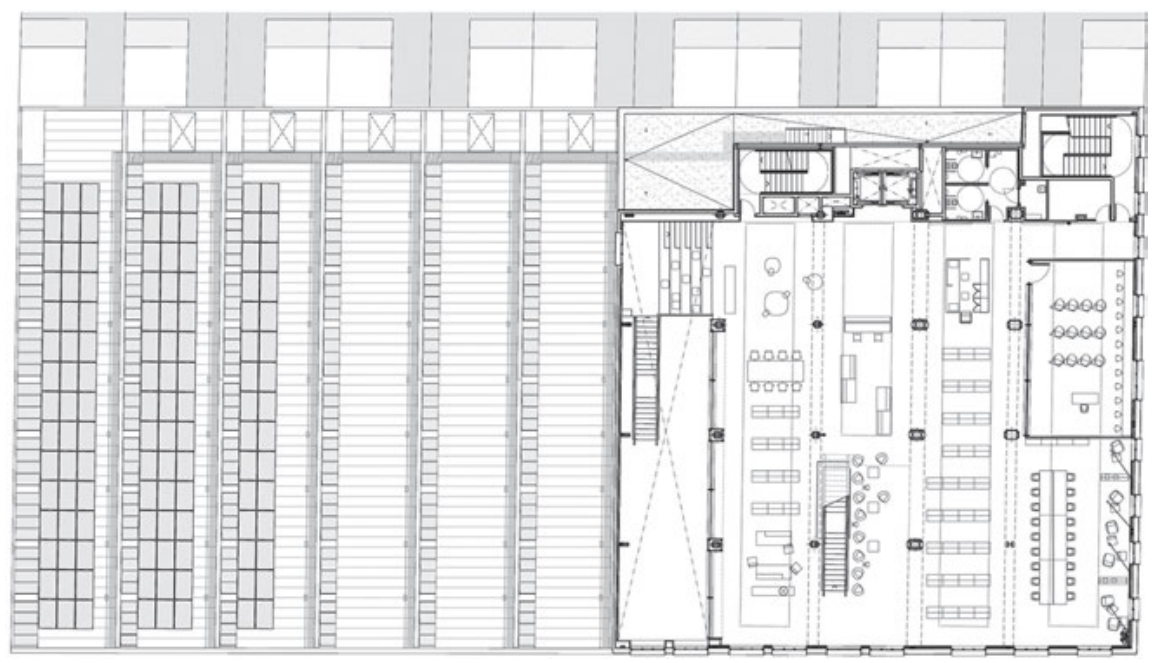

Fig. 4: First floor plan. (C) Ricard Mercadé Aurora Fernández arcquitectes.

\section{Historical Note}

Les Corts neighbourhood was originally a mainly rural municipality adjacent to Barcelona. The advent of electricity in the interwar period led to its industrial development. One of the most important factories to be installed was that of Gabriel Benet Campabadal (Figure 5), which housed some one hundred power looms that wove a broad range of products such as bobbin lace and silk ribbons (Figure 6).

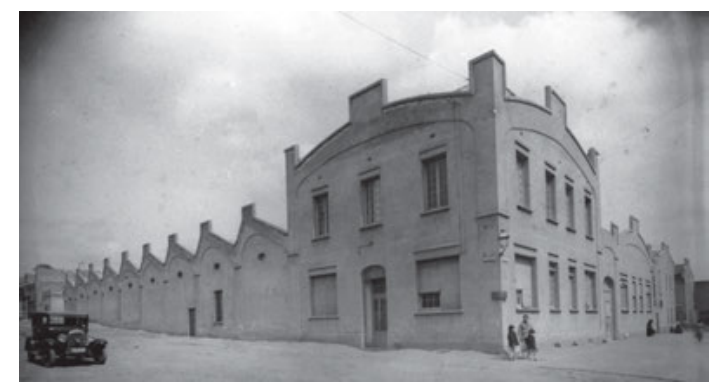

Fig. 5: Benet Campanal factory. (c) Antoni Pons article from Col-legi d'Arquitectes de Catalunya (COAC) Historical archive $\mathrm{X}$.

The factory's original design, dating from 1924, was by Antoni Pons I Domínguez. It comprised a building with a sawtooth roof, where production took place, and a corner building for offices (Figure 5). In the industrial building, the architect 
applied modernism and eschewed the Noucentista (https://en.wikipedia.org/ wiki/Noucentisme) classicist ornamentation, which was popular at the time, to create a modern plant using innovative structures and materials, such as reinforced concrete and glass. He did this without the traditional Catalan vault (https://en.wikipedia.org/wiki/Catalan_vault) or thin tile-vaulting, using reinforced concrete in the repeating structures instead. The factory was one of the first buildings in which reinforced concrete was used. The corner building underwent many transformations over the years, with rooftop additions and extensions that impaired its original appearance.

By the 1950s, Les Corts neighbourhood had been fully annexed by the city of Barcelona. Industrial activities that could be harmful to people began to be controlled, which led to the closure of most of the existing industrial facilities, including the Benet Campabadal factory. The revaluation of land for the construction of housing caused many industrial facilities to be replaced by residential complexes. The few factories that remained are those which changed their use, one of them being the Benet Campabadal factory which as noted above was occupied by the Barcelona Glass Centre Foundation with the industrial building, the most emblematic part of the complex, becoming a municipal warehouse in 1990.

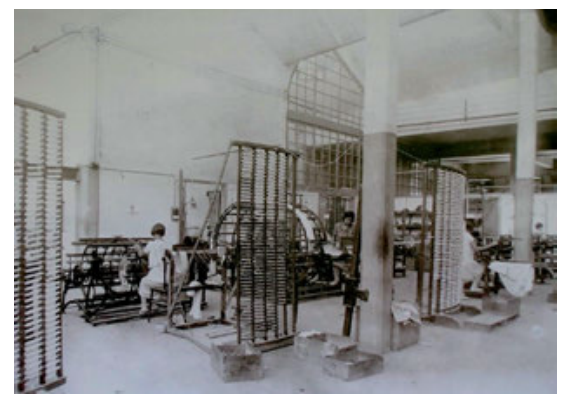

Fig. 6: Workers making ribbons in the old factory (1930). ( ) Municipal archive of Les Corts District.

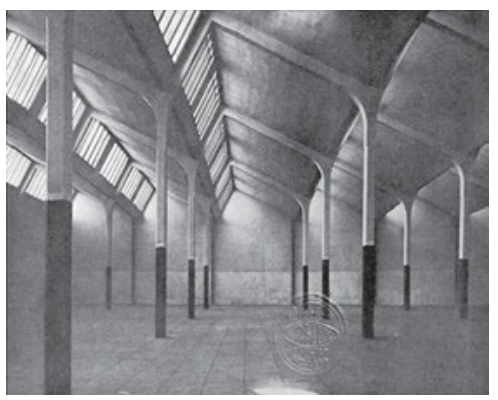

Fig. 7: Interior before rehabilitation. (c) Antoni Pons article from the Architects Association of Catalonia (COAC) Historical archive.

\section{The Beginning of the Rehabilitation Project}

The rehabilitation of the former factory (Figures $7,8,12$ ) began with the commissioning of the project through an open tender sent out by the Barcelona City Council in 2010. It turned out to be a long process, with the work being completed at the end of 2017. 


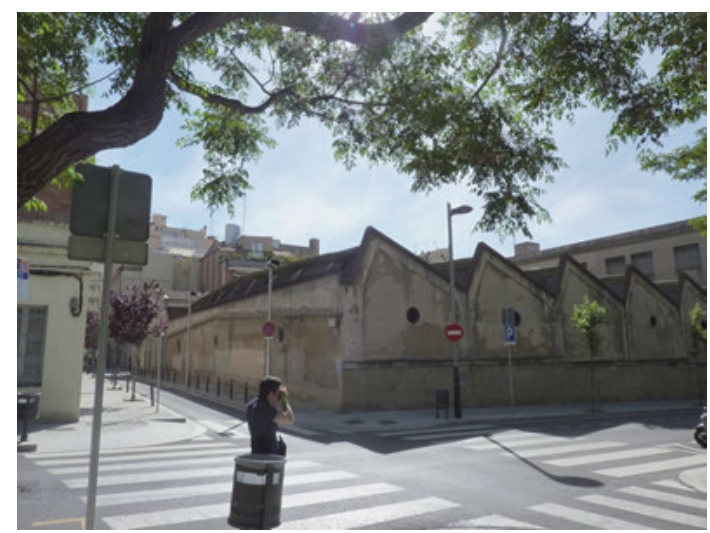

Fig. 8: Initial building. (C Ricard Mercadé Aurora Fernández arcquitectes.

On the first visit to the site, the building was surveyed to establish how it had deteriorated over the years in order to understand what needed to be done and to highlight the qualities of the original structure (Figures 7, 8, 12). Due to several interventions, the building was in a sorry state by the time the project got underway. The corner building was of little architectural value and the quality of its construction poor. There were mezzanines as well as rooftop additions built to take advantage of the available space, and the original front façade had been disfigured by various alterations. The corner building's structure was of inferior quality and in a poor state of repair.

The outstanding value of the complex lay in the industrial building itself and specifically in its structure, which had been designed by Robert Maillart, a renowned Swiss engineer. Six bays defined a structure formed by a grid of very slender poured-in-situ concrete columns which, where they reached the roof, adopted a Y shape, dividing into two parabolic beams. Built on a rectangular plan, the building had an area of approximately $1,000 \mathrm{~m}^{2}$ and a free height of $6.20 \mathrm{~m}$. The roof formed by a saw-tooth structure with continuous skylights presented a northern exposure, providing natural lighting free from glare, deemed very appropriate for the building's use as a library.

If a new building had been designed to house the library, such a tall space, originally conceived to accommodate the factory's big looms, would not have been envisaged, but it is the graceful proportions of the former factory with its elegant elongated shape that make a great impression on visitors and were advantageous in installing the library in an existing industrial building. The decisions that were made in the process of designing the building were taken with a view to enhancing the positive features of the existing structure and to adjusting the elements that were not so favourable for the new use. The impressive size of the space is one of the building's foremost qualities. 
Conceptually and functionally, industrial buildings constitute self-contained inward-looking structures, the opposite of what is required of a public building, which should relate to its surroundings and neighbourhood. The creation of a clear connection between the interior and the exterior was one of the major challenges of the project, and several different approaches were taken to achieve the desired outcome. Firstly, it was necessary to provide the new building with a main entrance, since there was previously only a small door for factory staff access.

The new entrance is in the corner building and forms a large opening thanks to the underpinning of the whole façade, achieved by installing a large post-tensioned concrete girder. The result is a clearly visible entrance to the library, complemented by glazed enclosures that act as display windows, allowing what happens inside to be seen from outside. Both the beam and the walls that support it are made of béton brut/raw concrete with a prominent surface texture produced by board marking that contrasts with the lime stucco of the façade, evidencing the fact that it is a new intervention which does not mimic the original structure (Figure 9).

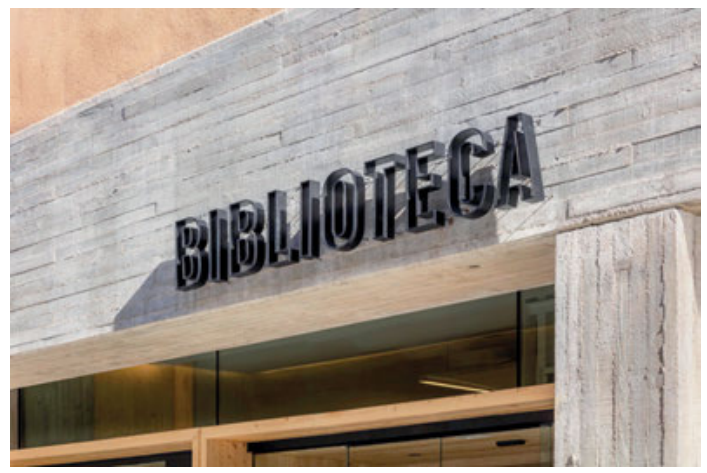

Fig. 9: Textured béton brut. (c) David Cardelús.

Secondly, an intervention was carried out at the rear of the industrial building, which had a blind wall devoid of architectural interest. It involved opening the whole façade to the exterior, replacing it with a glazed enclosure in the form of a curtain wall, which is perceived as an extension of the skylight on the roof. By eliminating the sense of a walled-in space, a direct outdoor-indoor visual connection is achieved and people walking up from Carrer Comtes de Bell-lloc can see what is happening inside the library (Figures 10 and 11). 


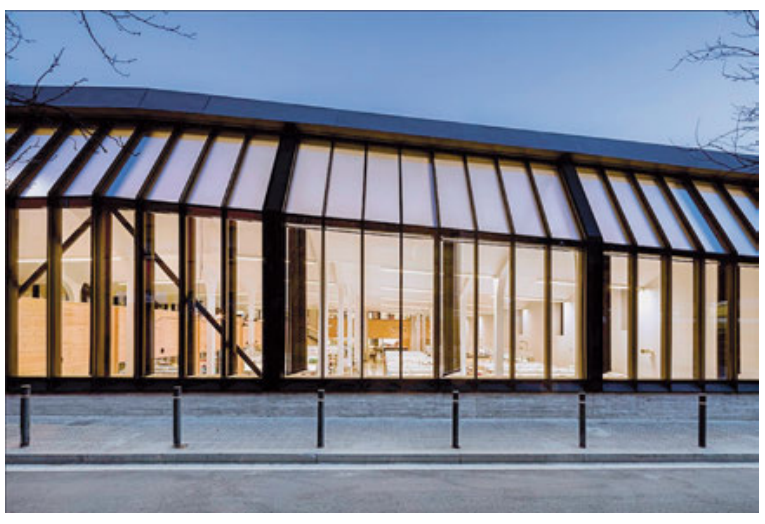

Fig. 10: Opening the whole façade to the exterior. (C) David Cardelús.

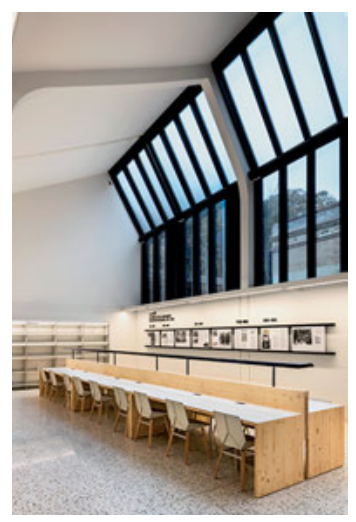

Fig. 11: A direct outdoorindoor visual connection. (C) David Cardelús.

Thirdly, some minor interventions were carried out. For example, the round oeil-de-boeuf windows on the longitudinal façade overlooking the street were replaced by elongated windows that follow the curved contours of the beams. The windows provide a view of the outside from everywhere in the building, while highlighting on the façade the original structure's graceful proportions and formal beauty.

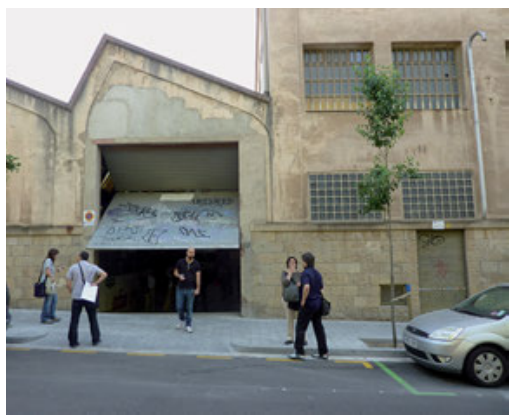

Fig. 12: Original building. (C) Ricard Mercadé Aurora Fernández arcquitectes.

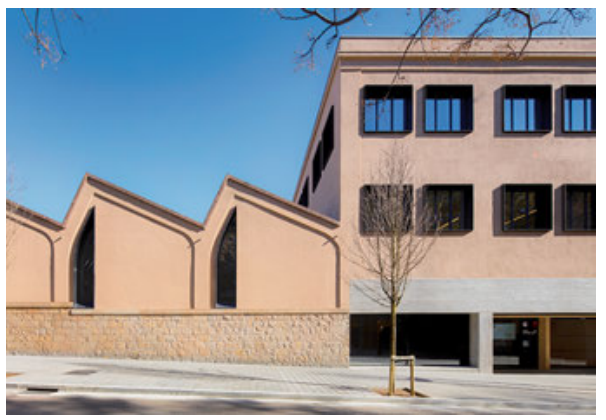

Fig. 13: Completed project. (C) David Cardelús.

Another challenge was to link the various floors and spaces of the building. The intention was to make them easily accessible to users both physically and visually, so that the building could be understood from the entrance hall. The intervention involved transforming the loading bay adjacent to the corner building 
into a vestibule in which the visual and spatial connection is made apparent. The building's main entrance is located in the vestibule and it became the hub of the project through the creation of a double-height light-filled space featuring an open stairway. The entrance hall guides visitors to the upper floors. In the open spaces, a sculptural stairway has been designed with the béton brut striated texture, clearly identifying it as part of the new intervention (Figure 14).

To accommodate the entire functional programme, it was necessary to increase the net area of the structure by building a mezzanine that occupies two bays of the industrial building parallel to the party wall. The elevated position is of great interest since it offers a new view of the industrial building and a different perception of the space located near the saw-tooth roof. Beneath the mezzanine lies the children's space, which is separated by a glazed enclosure and is connected to a new exterior courtyard where outdoor activities can be held.

\section{Rehabilitating Without Interfering}

Flexibility is essential in the conception and design of any building, but even more so when a public facility is involved. Such a building must be a living structure, capable of adapting itself to various users and uses, to changes of layout, and to technological advances. Indeed, changes today are occurring faster than ever before.

Regarding layout, the building's flexibility and adaptability are ensured by keeping the floors as unencumbered, open and light-filled as possible with the enclosed areas arranged in a compact group abutting on the party wall. The enclosed spaces include lifts, stairs, toilets and storage areas for equipment and facilities. Equipment and facilities should also comply with the need for flexibility. Technically it was not feasible to install a raised services' floor since it would not then have been possible to provide underfloor cooling/heating. Consequently, a distribution network of electrical and data wiring was designed with uniformly distributed outlets to allow adaptation to future changes.

One of the major difficulties of rehabilitating an old building whose use is to be changed, lies in the non-invasive integration of new technical, regulatory and structural requirements. The intention of the project was to achieve harmonious integration while maintaining and enhancing the character of the various spaces.

The existing structure did not have the necessary capacity to meet the new requirements for use particularly because of structural problems with the corner building. It was decided to strengthen the building with a free-standing metal structure like an exoskeleton that embraces both the columns and the beams 
(Figure 15). Allowing the visual identification of the original structure helps to preserve the historical memory while giving the reading spaces a unique character.

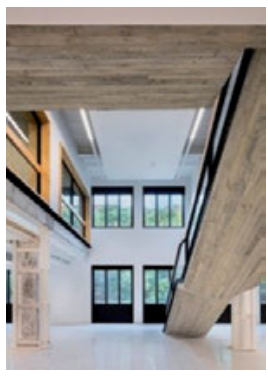

Fig. 14: Sculptural stairway with textured béton brut. (C) David Cardelús.

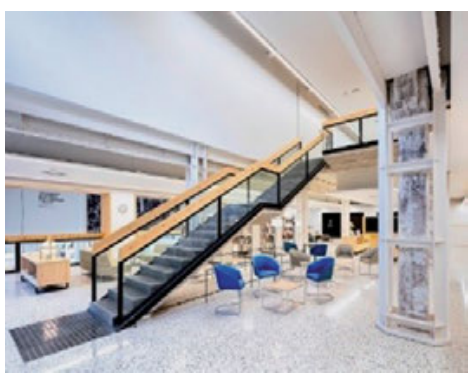

Fig. 15: Structural reinforcement of the columns. (C) David Cardelús.

The project was particularly complex, mainly because the aim was to avoid filling the ceiling with electric cableways and trays that would impair its appearance. An added complexity was the ceiling height, which tended to produce a stratification of the air, making it hard to achieve the required comfort temperature throughout the space. The problem of providing the building's heating and cooling system appropriately was resolved by installing radiant flooring, which provides both cooling and heating. In addition to being the least visually invasive solution, the system ensures the comfort of users, and is more efficient since it operates only when it is really needed. The difficulty lay in juxtaposing the circuit on the layout of the electrical and IT wiring, which was designed to lie under the flooring. It was necessary to implement an experimental solution with two layers of installation ducts and a uniform network of connection boxes containing the outlets, which are distributed with a sufficient density to ensure flexibility of layout and versatility of space use.

There is a more conventional solution for the rest of the building: the air conditioning is distributed through the ceiling. Even so, care was taken to ensure that the ceiling does not touch the original structure in order to keep old and new elements separate. Free-standing panels with sound-absorbing acoustic qualities were chosen. 


\section{Rehabilitating Involves Imbuing the Future with History}

The assignment of a new use to an industrial building in the city is what allows the structure to continue to exist, despite its location in an urban setting. The rehabilitation should take advantage of the building's assets and correct any shortcomings, without changing its essential character. It may be necessary to consider experimental solutions to overcome budgetary difficulties or the misgivings of technical experts.

The reuse of historic buildings on the grounds of sustainability alone may be difficult to justify. If the decision is based only on budgetary considerations and time available, then it is likely that there will be a different outcome. There are, however, intangible factors such as the preservation of the historical memory and the continued existence of exceptional buildings and spaces that tip the balance in favour of regeneration and reuse.

In this case, sustainability and energy efficiency were key to the whole project, hence the decision to obtain BREEAM certification, a prestigious and demanding international system that assesses environmental impact (https://www.breeam. com/). Sustainability and energy efficiency are more difficult to implement in rehabilitated buildings than in new structures. Steps taken included improving the envelope of the building with insulation and the avoidance of thermal bridges, together with the use of efficient heating/cooling and energy production systems; the production of energy by means of photovoltaic panels installed on the saw-tooth roof; the use of rainwater for the watering of indoor plants; monitoring energy consumption; and the incorporation of low-energy regulated lighting systems. Indeed, lighting systems of this type of work especially well in this industrial building. Thanks to the large quantity of northern light entering through the skylights in the roof and the detector system that automatically regulates the lighting, the artificial lighting system does not operate for much of the day. The day-to-day functioning of a cultural facility necessarily involves the consumption and maintenance of considerable resources, which must be rationalised and optimised to establish an environmentally sustainable management model.

The materials and colours used in the building were limited, with a small palette of colours to avoid drawing attention away from the space itself. They were chosen not to mimic the existing elements but to preserve the structure's industrial character. White was the main colour used, because of its clean and luminous appearance, with black on the metal elements and clear varnish on the woodwork to lend warmth and create a comfortable ambience for users. Béton brut with the texture of the wooden boards of the formwork was also used. The 
elements in the new intervention create a dialogue with, and a counterpoint to, the lightness of the metal structure.

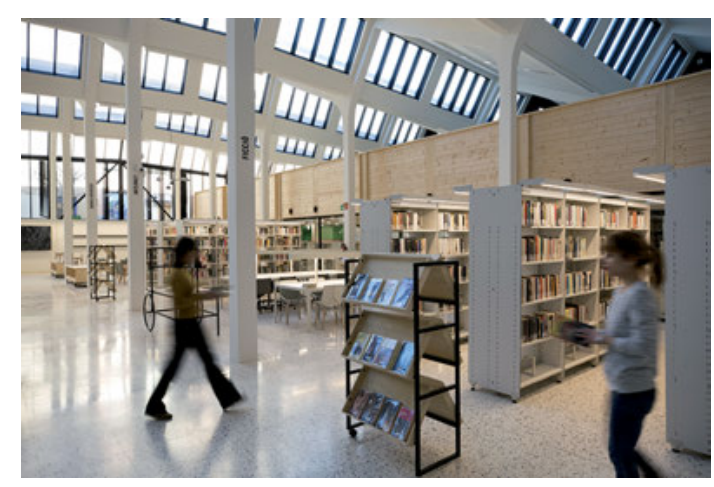

Fig. 16: Special racks and display units designed for the library. (c) Eva Guillamet.

The furnishings include many pieces expressly designed for the library with two objectives: to support different ways of using the building apart from reading, studying or working at tables; and in the large spaces to provide more intimate private areas at a human scale. The materials used in the furnishings all follow the same style using black-painted iron and natural wood, providing a unified overall image. In the main building, for example, there are spaces for meeting and working in groups, with seats and tables arranged to evoke the atmosphere of compartments of old-time train carriages. Surrounded by bookshelves, they have their own lighting to add to the feeling of shelter and privacy and have sound-absorbing panels to avoid disturbing other nearby users.

Books are not only to be found on the shelves. To catch the attention of readers and arouse their interest, books are clearly visible on specially designed racks and display units (Figure 16). Some units are in the reading areas, creating spaces with a domestic feel and featuring soft lighting to provide extra warmth.

\section{Urban Revitalisation}

The key design feature introduced to connect the library building with the city was the broadening of the pavement along Carrer Comtes de Bell-lloc, increasing its width from 2.9 metres to 5 metres. The broader pavement raises the profile of the public space, which is what the facility requires. In a second phase of the project a future urban redevelopment of the whole street is envisaged, with the 
creation of a public space of suitable quality in front of the library, entailing a major urban improvement scheme and an increase of pedestrian areas.

\section{Conclusion}

A restoration project can be considered a success if, on completion, the architect and the whole planning and construction process, no matter how complex, recede into the background and the building and its users come to the fore. The building should be self-explanatory with the original elements and the new interventions clearly identifiable and working together to form a harmonious whole. Success lies especially in meeting two goals which may seem rather obvious but are important: firstly, the building should function well at the time of opening while also being capable of adapting to future needs; and secondly, users should feel the building belongs to them and they should have a sense of wellbeing when entering the library.

The Montserrat Abelló Library project has encompassed the restoration of a building which embodies the history of Les Corts neighbourhood. After two years of operation and an analysis of the key indicators monitoring use, it can be confirmed that the opening of the new library has been a complete success. A comparison of 2018 data with that of 2019 shows a clear upward trend. The library is open from Monday to Saturday for a total of 56 hours and, with 14 staff, has recorded 429,401 visits, an average of 1,413 visits a day compared to 1,200 in 2018 in its second year of operation. Other statistics include: 6,337 new users registering since the library opened; connections through Wi-Fi services coupled with those on the 40 public use computers totalled 61,892 Internet uses; and 126,404 loans, an average of 416 loans per day, in 2019. A large part of the success is due to the library's well-chosen and varied cultural programme. In 2019, there were: 186 cultural and reading events with 3,649 participants; 136 digital literacy courses with 938 participants; 28 reading club sessions; and 35 school visits with 859 pupils involved.

The outcomes are incredibly gratifying for all who helped make the project a reality and confirm the potential value and usefulness libraries continue to have today as community-oriented neighbourhood facilities. 